\title{
THE FUNCTIONS OF FORMULAIC SPEECH IN THE L2 CLASS
}

\author{
Marie Girard and Claude Sionis
}

\begin{abstract}
This study deals with Formulaic Speech (FS) usage in the context of the partial L2 immersion class. It tries to define and classify FS according to its functions. The fact that learners resort to FS shows that second language production is not only based on the construction of sentences from scratch but also on the integration of formulaic sequences in discourse. But what is the use of FS? What are the possible functions it performs?

We attempt to show that FS makes up for a lack of structural knowledge and might therefore be used as a learning strategy in the acquisition of structure. Then we consider the psycholinguistic function of FS and try to demonstrate that it might be a pre-planning strategy and a way for the learner to economize effort on processing and thus focus on his or her learning of the language. Finally, the paper analyzes the communicative function of FS and its role in the relation between speaker and hearer, and suggests that it might play a part in the development of pragmatic competence.
\end{abstract}

Keywords: Formulaic Speech, Second language acquisition, Second language production, Partial immersion, Communicative competence.

\section{Introduction}

\subsection{Working hypotheses and aims}

In The Study of Second Language Acquisition, Ellis (1994) suggests that the use of formulaic speech may be one of the early developmental stages of second language acquisition, after what he calls the silent period stage and before the semantic and structural simplification stage.

The present study was prompted by the hypothesis that formulaic speech (henceforth FS) used by young L2 learners could be more than dead or amorphous stretches of language imposed upon, or freely chosen, for politeness or other socially justified reason. FS are considered to be more than ready-made lexical short-cuts to refer to stereotypical objects or actions or any other evidence of 'lazy' language behaviour. Another study (Girard \& Sionis 2003) has attempted to identify and classify FS in the same context. We kept in mind the two basic categories of FS which young learners might resort to: The first includes the "conversational routines" (Aijmer 1998) or "situation-bound utterances" (Kecskes 2000) which are context- and/or situation bound and the second covers FS such as idioms, collocations, etc. which are not situation-bound. Its possible supportive and facilitating role in language production is highlighted here by the study of its functions in L2 classes.

The study attempts to define the areas of second language use for which FS is likely 
to make up for a lack of structural knowledge (the use of functional items, mainly), and how FS is integrated into the general speech structure. Finally, we consider the various theories concerning the role of FS in the acquisition of a second language, to demonstrate that FS can be considered as a learning strategy.

\subsection{Observation and data collection procedures}

The following section is taken up verbatim from Girard \& Sionis (2003) since the project and its circumstances are the same.

The analysis is based on the observation and recording of oral communication in a class of fifteen children aged five to seven, learning English in a partial immersion program (some subjects of the curriculum are taught in English every afternoon) in a small primary school in Nantes, France. As most of these children are at an early stage of L2 acquisition, their morphosyntactic development was thought to be worth examining.

It seemed interesting to observe a group of young learners in an immersion class, because this provides broader information than a single individual's case study, and because the children's productions in the immersion classroom were expected to approximate naturalistic second language production. Usually, total immersion consists in giving education (i.e. the whole regular national curriculum) in a foreign language. In the present case, the children learn math and science in French in the morning and have other activities in English with a twenty-five-year-old Welsh teacher in the afternoon. The teacher resorts to a method based on short videos and interactive role-play games. There were fifteen children aged five to seven at the beginning of the observation. All of them were French, with French-speaking parents, except for a Rumanian boy, whose mother tongue was Rumanian, who had already started learning English in an international school and was currently learning French.

The recording sessions turned out to be of variable length since they depended on holidays, extra-curricular activities, teacher's sickness, and even strikes. The recordings covered a period of two months, between the end of November 2000 until the end of January 2001.

We had to base our reflection on other researchers' data bearing on conventional L2 learning, because it turned out that the communicative situation in the classroom was closer to regular foreign language teaching in primary schools than actual immersion teaching, in the sense that it did not resemble naturalistic language acquisition as much as expected. English was introduced to the children mainly as a subject to be learned rather than as a medium through which other subjects are learned, nevertheless, the observation did provide a few insights into the various functions of FS in second language production.

As far as data collection itself is concerned, we only transcribed sequences in which English was used and numbered them from (1) to (396), according to boundaries corresponding to a minimal exchange of information ${ }^{1}$. What is meant by 'minimal exchange' is an interactive situation in which a piece of information provided by one or several speakers is complete. So each sequence corresponds to a new piece of information.

Most of the time, the minimal exchange consisted in a question-answer pair, or the

${ }^{1}$ For reasons of space, the full corpus is not given here but it is available from the authors. 
interactive building up of a single sentence. All exchanges in French were removed, except when they revealed transfer phenomena, and all comments from the teacher that did not involve a response from the children were also suppressed, because the focus was to be on the children's speech only.

\subsection{The partial immersion situation}

The following is a definition of immersion given by Hamers and Blanc (1989: 265-267):

BILINGUAL EDUCATION: Any system of education in which, at a given point in time and for a varying length of time, simultaneously or consecutively, instruction is given in two languages.

IMMERSION PROGRAM: A type of bilingual education in which a group of learners is taught through the medium of a language different from their mother tongue, the latter being introduced later.

PARTIAL IMMERSION: immersion program in which both the first and the second language are used as media of instruction.

The program we observed corresponds to a partial immersion program. In it, the children still speak occasionally in French to each other, though transfer phenomena in their use of French sometimes occur:

(60) ALINE: Regarde, en fait - J'peux lui traduire? - La petite main elle peut aller partout, mais la grande elle peut aller que sur celui-là et celui-là.

(Look, in fact - Can I translate that to her? - the smaller hand it can go anywhere, but the bigger one it can only go onto this one and this one (comment on how to read time on a clock, Aline uses "main" instead of "aiguille" to means the hands of a clock (hand is "main” in French)))

(117) AGATHE: ma préférée chose, c'est les les (My favourite thing, it's the the)

Immersion programs are often praised for their results, which seems to be due to several factors, one of them being the widely debated age factor. As Larsen Freeman (1991: 140) suggests, the success of immersion programs "may be due to the greater amount of exposure to the second language that immersion children receive (time on task) and to the fact that the children are self-selected". Hatch (1983: 192) also highlights the fact that "children are highly successful because of the small range of types of communication they require, while adults may appear unsuccessful because of the large range necessary for interaction at adult level." Krashen, Long and Scarcella (1979: 573), in a review of the literature, give evidence for three generalisations regarding age, rate, and eventual attainment in the second language:

1) Adults proceed more rapidly through the initial stages of syntactic and morphology development than children 
2) Older children acquire faster than younger children

3) Acquirers who begin second languages in early childhood through natural exposure achieve higher proficiency than those beginning as adults.

Their basic position is that older is faster, but younger is better in the long run. We shall not go into more details on the efficiency of immersion programs and child second language learning, though these are two key issues in second language acquisition research. Moreover, the observed program happened not to correspond to the usual definition of immersion. According to the Center for Advanced Research on Language Acquisition (University of Minnesota), immersion is the "delivery of the curriculum in a second language to students who share the same first language". In immersion, contrary to other language teaching situations, the second language is not just the object of the teaching, but above all the medium through which the learning is done. In the partial immersion program we observed, the second language tends to be the main object of the teaching, except for one session during which the children use English to make a cake. During that session, the language production in English is far less important than in other sessions, because the children are not forced to produce through practice drills. The other sessions follow a roleplay pattern, related to FS and gestalt learning, and described as such in the teacher's handbook (Manuel 1990: 4-6):

Video tapes help the child to learn "real-life" language by understanding this language globally, and by identifying with the characters (puppets and children) (...)

It is not necessary to learn whole role-plays by heart but simply to repeat the language easily following the right intonation. The aim here is to give children an early means of appropriation before getting them to use the linguistic elements they know freely and correctly, by means of other stimuli. The first stimuli are substitutions aimed at creating new situations, either in keeping with the child's imagination or with the teacher's suggestions.

The partial immersion class observed therefore cannot be thought of as really representative of partial immersion education in general. The fact that the teaching method itself is aimed at practicing formulaic sequences is most likely to have influenced the data. Roughly speaking, social interaction resembles regular classroom interaction. Nevertheless, the communicative function of FS appears through simulations of standardized social interaction, which makes it possible to analyze the influence of the communication situation on FS.

The amount and nature of FS are therefore likely to vary according to the communication situation. Table 1 shows variations in the use of FS according to only two types of communication situations, but FS occurred in too many other situations to be given exhaustively here. Other very different types of communicative situations included telling name and age, asking for permission, socializing, expressing likes and dislikes, describing pictures, etc. Holophrastic speech (i.e. the use of one-word utterances, which corresponds to a semantico-structural simplification strategy) was preferred to FS when the children were asked to provide answers to the teacher's non-formulaic questions, to make personal comments or to tell a story. There was very little interaction in English between the children, and when that occurred, they used both holophrastic and FS. In fact, FS was abundantly used in role-plays, which were based on the practice of very idiomatic 
exchanges, that is, socially and culturally defined conversations such as telling time, socializing and asking for permission.

This is the reason why most of the formulaic sequences in the observation are tightly bound to the context. For example, a question such as What time is it? will not appear when the children are practicing the "salesperson" role-play. However, a few formulaic sequences occur throughout sessions: "Can I__?", "Can I go to the toilet?" and "chocolate cake" seem to be the least context-bound sequences. The first two formulaic sequences are aimed at addressing the teacher to ask for permission, either to go out of the classroom (when "Can I_" is followed by a verb phrase) or to get one's turn to speak (when "Can I" is used on its own). These formulaic sequences guarantee basic teacher-pupil interaction in English, and are encouraged by the teacher, as in the following example:

(237) ALINE: J'peux aller aux toilettes?

T: Sorry?

ALINE: Can I go to the toilet please?

"Chocolate cake" is used between pupils as a sort of private joke and most of the time spelt out in a sing-song manner. Its "private joke" status has taken over its primary communicative role. Therefore, even if the communication function of these formulaic sequences is valid for the classroom situation, it is not necessarily valid in other contexts.

\begin{tabular}{|c|c|}
\hline $\begin{array}{c}\text { TOPIC AND LANGUAGE TASK } \\
\text { Corresponding sequences }\end{array}$ & $\begin{array}{c}\text { FORMULAIC } \\
\text { SEQUENCES USED } \\
\text { The number of occurrences is } \\
\text { indicated between brackets }\end{array}$ \\
\hline $\begin{array}{l}\text { Social interaction and asking for foodstuff } \\
\text { Role play } \\
\text { Sequences (5) to (46) }\end{array}$ & $\begin{array}{c}\text { Can I have ___ please)? (20) } \\
\text { Good afternoon. (6) } \\
\text { How are you? (4) } \\
\text { Thank you. (4) } \\
\text { Can I__? (3) } \\
\text { Here you are. (2) } \\
\text { That's all. (2) } \\
\text { Fine,thank you. (2) } \\
\text { Good bye. (2) }\end{array}$ \\
\hline $\begin{array}{l}\text { Telling time on a clock } \\
\text { Sequences (48) to (65) }\end{array}$ & $\begin{array}{l}\text { What time is it? (7) } \\
\text { (it's)__o'clock. (4) } \\
\text { (it's) half past _.. (4) } \\
\text { Can I__? (3) } \\
\text { Can I go to the toilet? (1) }\end{array}$ \\
\hline
\end{tabular}

Table 1. Communication situation and use of Formulaic Speech.

To summarize our observations of FS in the partial immersion class at this stage, we could say that it plays a part in the adaptation of the learner's speech to the context, and therefore helps the learner to reach efficient communication with few linguistic tools. FS subsequently has an important role in the development of communicative competence, which goes along with social integration in the native speaker community, as we shall 
attempt to demonstrate further on (see 6. Communicative function: Formulaic Speech as a social integration device.)

\section{Early structural knowledge and Formulaic Speech}

A first preliminary observation is that there is often a discrepancy between the developmental stage reached by the learner and the syntactical level of formulaic expressions. Peters (1983; in Baigent 1996), suggests that "the children perpetrators of formulas are unable in other utterances to handle the same complexity of grammar, or do not use formulaic words in other utterances".

Among the many occurrences of FS observed in our corpus, the spontaneous and relevant use of abbreviated verb forms: "No, I don't", "it's not", "yes, I am", etc. in answer to teacher-prompted repetitions is clearly the result of unanalysed re-use, as the confusion It's not/I'm not shows in the following two examples.

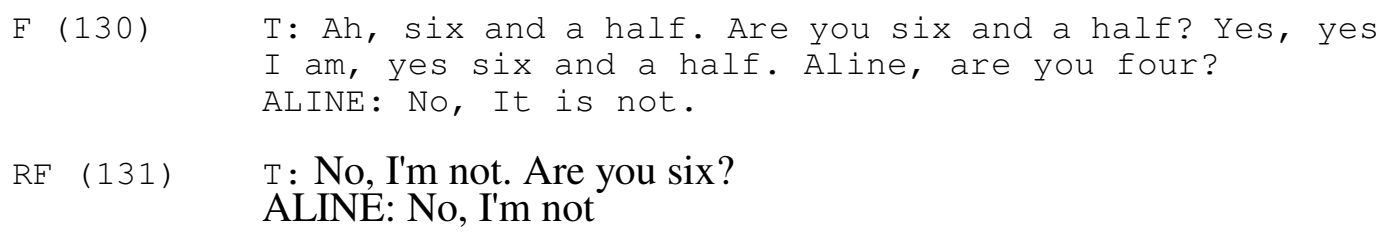

Never did the teacher ask a learner to do an exercise like: "complete the sentence: I'm not seven and $a$ half

It might then be useful to briefly investigate various aspects of the children's speech system to make sure that the structural knowledge necessary to build a formulaic sequence is not already available when the formulaic sequence is produced. If the answer were yes, the main justification for resorting to FS (convenient to use because it saves the trouble of parsing language items) would vanish. Radford (1998) suggests that early interlanguage lacks functional categories, mainly complementizers, auxiliaries and determiners. So maybe FS serves as a sort of functional prop to replace the missing knowledge of functional items and therefore helps the learner to avoid telegraphic style while conveying the right meaning. That is the reason why we decided to look at the children's complementizer system, more specifically in the case of questions, then turn to their inflectional and verbal systems, and finally assess their nominal system.

\subsection{The children's $C$-system: the case of questions}

A complementizer, as defined by Radford (1997: 499), is

a presubject position in clauses (or complementizer position) which is typically occupied by a complementizer like that/if/for, but which can also be occupied by an inverted auxiliary in sentences such as "Can you help?" where can is taken to occupy the complementizer position in the clause (...) A CP (i.e. complementizer phrase) is a phrase/clause headed by a complementizer (or by an auxiliary or verb moved into comp).

We only consider the complementizer system in questions, because the children 
observed in the partial immersion classroom do not resort to embedded clauses.

It seems that, even though the children are able to ask questions such as "What's your name?", they have not developed a complete C-system yet.

Radford (1998: 131) accounts for this phenomenon in precise syntactic terms:

a) Who did you play with? -Me

b) What have you bumped your head on? -Me

Both children here seem to misinterpret the initial wh-NP as a subject, and hence respond as if they were answering questions such as "Who played?" and "Who bumped their head?" (...) The answer we shall suggest here is that children at this stage have not yet acquired the syntax of the C-system, and thus not only are unable to produce structures involving preposed wh-phrases in the C-specifier position, but also are unable to parse adult utterances containing preposed wh-phrases correctly.

The phenomenon described by Radford (1998) is also observed in our immersion classroom:

(393) T: He's washing a bowl. And what is he washing the bowl with? What's this? What is he washing the bowl with? Gaspard, what's this? What is he washing the bowl with? He's washing the bowl with a...

C: The bowl

Here again, the child does not seem to be able to parse the wh-question and provides an element taken from the question in near random fashion as an answer.

It seems that the formulaic sequence or the teacher's prompt help to make up for the lack of a C-system, as in the following example, in which the teacher's prompt seems to have a "triggering effect":

(61) T : Thank you, Aline. OK what-

DAPHNE: time is it. What time is it?

The children in the immersion classroom do not seem to have developed the syntax of questions yet, but still they can resort to a large set of formulaic questions to carry out their communicative needs such as What time is it? or Can I go to the toilet?:

(237) ALINE: J'peux aller aux toilettes?

$T$ : Sorry?

ALINE: Can I go to the toilet please?

(63) AGATHE: What time is it? What time is it?

\subsection{The children's inflectional and verbal system}

Children seem to avoid verbal and auxiliary structures, by reducing them phonologically. In example (382), Lisa replaces copulas by a humming sound [an ], and in example (392), she avoids using the verbal and inflectional forms is washing with that same sound [an ] .

(382) LISA: Emm Axel [an] bigger emm Theo [an] smaller (omission of copula) 


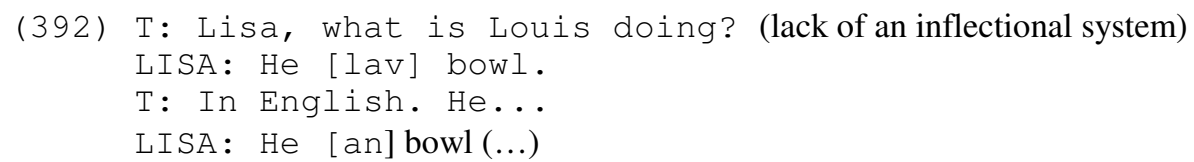

Children in the class observed also tend to drop subjects:

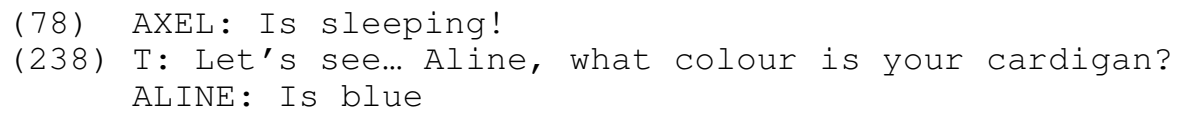

The observers noticed that these children also tend to use verbs in a holophrastic way:

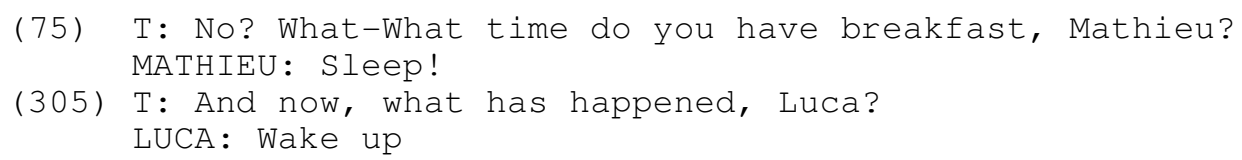

Another clue in support of the argument of a limited syntactic knowledge was that the children dropped morphological inflections:

(309) T: His hat. And now, what is he doing? MATHIEU: He run

However, in this example, when the teacher corrects Mathieu by providing him the formulaic prompt "He is _ ", the child automatically uses the correct verb form -ING:

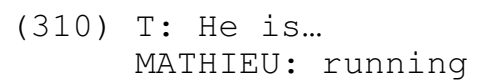

These examples do not necessarily prove that children actually lack an inflectional system, as Radford (1998) suggests. Pierce (1992) demonstrates that children might use covert forms for subjects, for example, in the specifier position of IP (i.e. the position that precedes the inflectional head of the containing phrase) before integrating the rule that English is a non PRO-drop language, or in other words, that English sentences require an overt subject.

The errors listed above (avoiding or replacing verbal and auxiliary structures, dropping subjects, using verbs in a holophrastic way, and dropping morphological inflections) are frequently described in second language studies. However, they do not occur within the formulaic sequences used by the children in the partial immersion class. The difference between the syntactic level of the creative (FS-free) speech produced by the children in the partial immersion class and that of the formulaic utterances they resort to is too big to suggest that FS might be located at an intermediary level between two stages. The same can be said for the use of negative patterns. Most of the time, negative answers are given in the form of the holophrase "no". Otherwise, negative sentences are created by preposing "no" to a verb base, or even a noun phrase, much like some Creole constructions: "he not eat", mentioned in Arends et al. (1995: 129) quoted by Singh (2000)

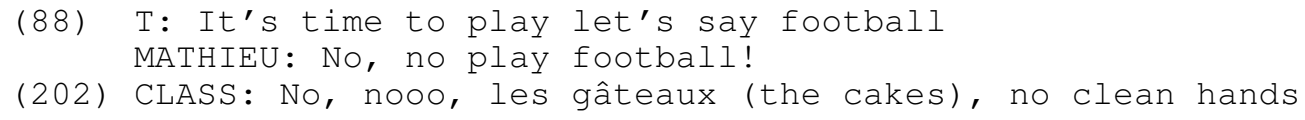


This pattern is typical of early interlanguage stages, and is also valid for other languages, as is shown by Luca's use of non+VB and no+VB when speaking French (which is not his native language):

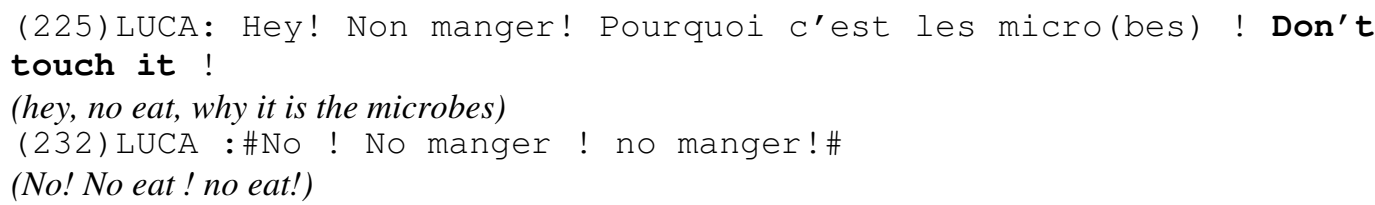

Our interpretation of the discrepancy at the structural level between complex but unanalysed FS and creative but relatively unelaborated speech is that FS is likely to be used as a strategy to make up for a lack of structural knowledge.

\subsection{The children's nominal system}

Most of the time, whether in spontaneous production or in sequences of creative speech embedded in formulaic frames, children tend to drop determiners:

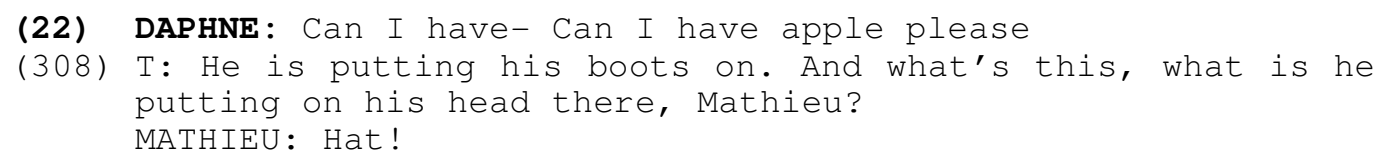

However, sometimes, they seem to have some sense of the structure of compounds:

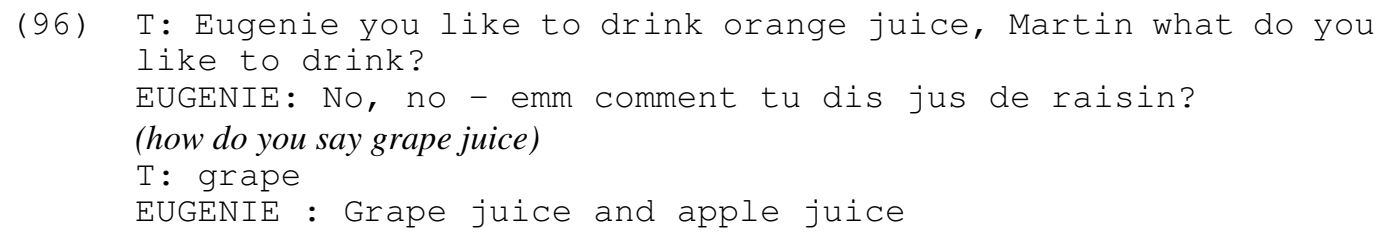

Here, Eugénie is able to build a compound from only one of the two nouns that compose it. The case may be that she takes the expression "orange juice" as a model since it was provided by the teacher.

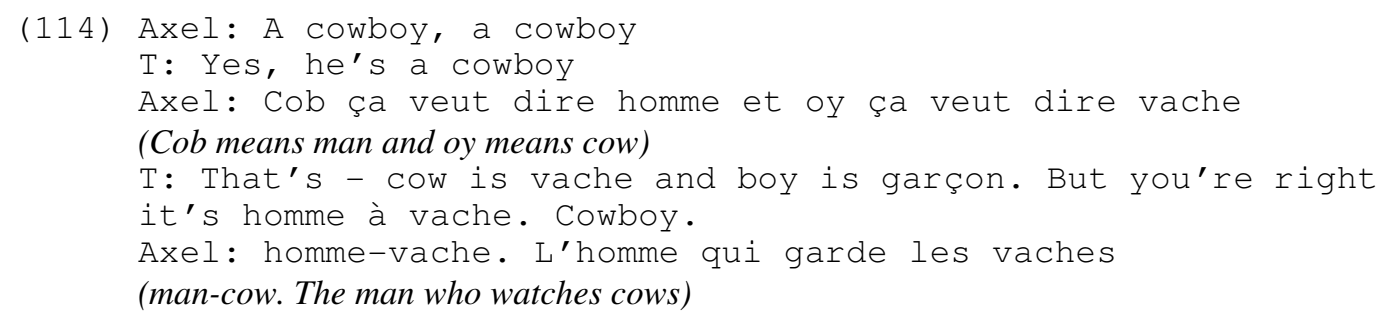

Even if he is not able to parse the two words that make up the compound, Axel knows that there are two words made into one. However, it might be possible that somebody told him. In the following examples, Lisa seems to rely on the formulaic sequence to provide the determiner: 
(38) LISA: Can I have a chips please?

(39) LISA: Thank you. Can I have a biscuit?

(40) LISA: Thank you. Can I have a chocolate cake, please?

From this observation of the various aspects of the children's structural knowledge, the same conclusion can be drawn as in Clark's study $(1974,4)$ that "a number of routine unproductive sequences seems to co-exist with a few simple productive rules". But what do these unproductive sequences become? Are they progressively discarded as the productive rules grow more complex, or do they remain as such? How are they inserted into the general speech structure?

\section{The creative construction of formulaic speech}

Researchers who consider FS from a structural or linguistic point of view generally argue that it progressively evolves into a more creative type of language. However, they do not necessarily agree on how this evolution takes place.

Wong-Fillmore (1976) views integration phenomena as the proof that FS serves as input for the development of creative language. According to her, formulaic language is subject to an analytic process in much the same way as the rest of the input, but this process takes more time for formulaic sequences, which would imply that FS is not so different in nature from creative speech. On the contrary, for Krashen and Scarcella (1978), even if routines and patterns could conceivably serve as input for the creative construction process, this input is probably insufficient for successful language acquisition.

For that matter, some of the children in the classroom seemed able to parse the formulaic input, but that phenomenon remain restricted to translation, and only for compounds, maybe because these nominal forms are those they feel the most comfortable with.

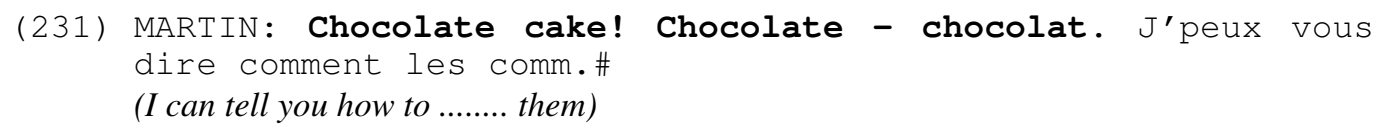

In the following example, Aline makes a metalinguistic comment on how she parsed a formulaic sequence, but we are not sure what interpretation should be made of the comment:

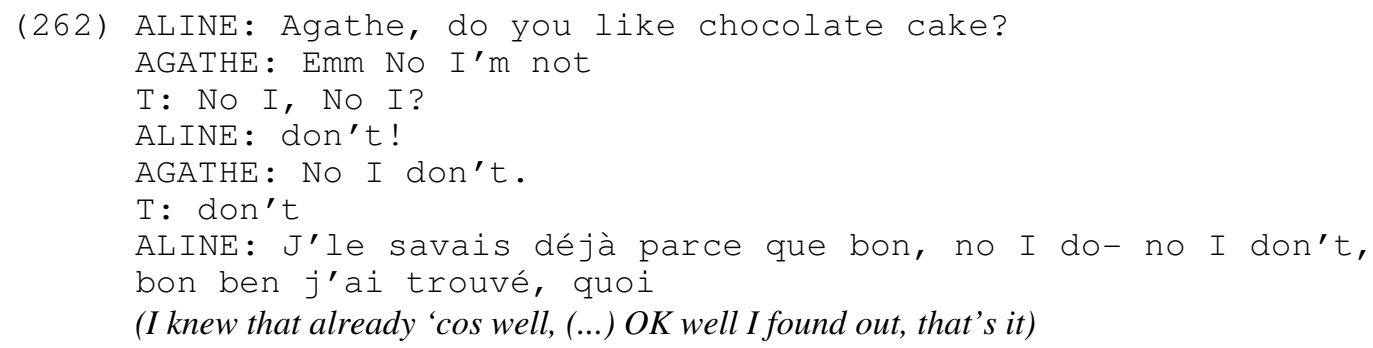

For Clark (1974), FS is integrated into a more general structure either by combining two formulaic sequences or by embedding a formulaic sequence into a simple utterance 
type. The children in the immersion classroom actually did embed FS but they did so by inserting those formulaic bits into French utterances:

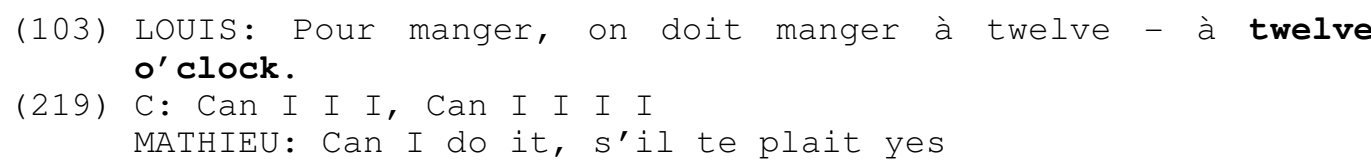

The following two sequences are examples of possible juxtaposition, the first being an example of combination of an amalgam with a formulaic sequence, and the second the combination of two formulaic sequences:

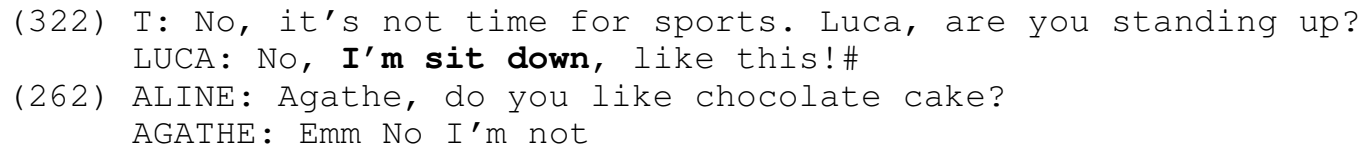

FS may be integrated by juxtaposition with a repetition of the previous utterance, as illustrated by Wagner-Gough (1975, in Larsen-Freeman et al., 1991: 69):

The subject, Homer, an Iranian child aged 5 years and 11 months, produced utterances such as "where are you going is house". Homer's utterances are uninterpretable if we limit ourselves to examining his performance. Only when we look at the input preceding Homer's utterance can we make sense out of it. Homer's utterance is offered in reply to an adult's question, "Where are you going, Homer?" Homer's strategy in answering questions in English was to incorporate the question along with his answer, a strategy referred to as incorporation.

In the following example, Mathieu combines the formulaic sequence used in negatives It's not__ with a section of another formulaic sequence or with a repetition of the previous sentence to create his spontaneous answer:

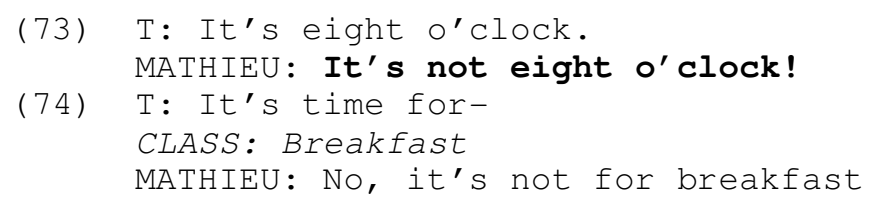

For Rescorla and Okuda (1987: 283), the learner's language develops by building up longer units from small modular components, "making syntactic constructions using modular patterns as building blocks or elements, rather than by using individual words as the structural components of sentences". They mention how Peters (1983) distinguishes two types of integration:

-Horizontal integration: big $+X \&$ hot $+X=P R O P E R T Y+X$

-Vertical integration: $b i g+X \&$ see $+X=$ see big $+X$

Some theories consider that vertical constructions, which are learner utterances formed by borrowing chunks from the preceding discourse and then adding to these from the learner's own resources, are the precursors of horizontal constructions. In both cases, there is a "constant + variable" scheme that is subject to a generalization strategy which leads to productive syntax. 
There are no examples of such integration in our corpus. There are several possible reasons for that: Either it is too early in the children's interlanguage stage to exhibit such phenomena, or if it is a long-term process, the observation is not long enough. Another possibility would be that this process does not exist at all.

There must be a way not to treat formulaic chunks of language as an exception to Universal Grammar principles and parameters. Cognitive grammarians make it fit into a more general theory that "views a construction as a kind of formula consisting of an ordered sequence of slots" (Taylor 1989: 198), each slot requiring a specific element, a noun or a verb, for example. Children do have some kind of categorical knowledge (maybe devoid of functional elements) needed to fill in the slots: They are more likely to misuse determiners and say *Can I have a soup? than to mix up grammatical categories and say *Can I have a eat?. However, this seems to depend on the sequence. A sequence like "It's _ " can be followed by either nominal or verbal elements. The interface between creative and FS, and the structural knowledge required to use formulaic sequences, certainly need to be further investigated.

In another study (Girard \& Sionis 2003), the authors have shown that FS was more to be defined in terms of its function rather than in terms of its structure. Indeed, FS is part of a larger system that intervenes at the pragmatic level. In that sense, the acquisition process can be seen as an evolution from a pragmatic mode in which word order prevails over a more syntactic mode in which morphology takes over (Givón 1979; in Klein 1986). For example, in the pragmatic mode, since function and word order prevail, there is no use of grammatical morphology, while in the syntactic mode, there is an elaborate use of grammatical morphology. FS then might play a part in that pragmatic mode and disappear as the shift is made towards the syntactic mode. Learners' use of such a discourse strategy to compensate for the morphological features they have not acquired might therefore play a part in the progressive grammaticalization of their speech (Ellis 1994: 285).

To sum up, FS might be integrated into the general speech structure either by juxtaposition, embedding or gradual evolution. In all cases, FS in the framework of linguistics is seen as a temporary stage of acquisition. If this is so, then FS is likely to be discarded once the next developmental stage is reached. But that does not seem to happen, and one might wonder if FS should be considered as a stage of acquisition or as a learning strategy.

\section{Formulaic speech as learning strategy}

According to Ellis (1994: 712),

\footnotetext{
A learning strategy is a device or procedure used by learners to develop their interlanguages. It is one type of learner strategy [behaviour or action that learners engage in, in order to use or learn the L2, generally considered to be potentially conscious, and therefore open to inspection]. Learning strategies account for how learners acquire and automatize L2 knowledge. They are also used to refer to how they develop specific skills. It is possible, therefore, to talk of both "language learning strategies" and "skill-learning strategies". Learning strategies contrast with communication and production strategies, both of which account for how learners use rather than acquire L 2 competence.
} 
As a temporary stage of acquisition, FS is likely to be a communication and production strategy, as we will try to show later. But could it also be a language learning strategy playing a part in the acquisition and automatization of second language knowledge? To what extent are formulaic sequences used in language?

Some authors like Baigent (1996) have suggested that FS plays an important role in language, others like Bohn (1986) or Krashen and Scarcella (1978) say that it is only occasional. Thus it seems relevant to evaluate the importance of the use of FS, because if used extensively, it might constitute a core element in language use and determine the construction of morphosyntactic knowledge. But if FS only occurs occasionally, it is not constitutive of language use and acquisition, and is just a short-term production automatism.

Hakuta (1974: 288) sees FS as a "temporary prop which temporarily gives support until a firmer foundation is built". In the same sense, some researchers suggest that FS is progressively replaced by syntactically flexible forms, and then its frequency drops to native-speaker frequency. Peters (1976; in Krashen and Scarcella 1978: 289) agrees with the idea that "Gestalt language may be a temporary strategy for the performer to outperform his analytic competence".

In our study, FS still seems to be used extensively, which might correspond to a specific stage in the children language learning curve. For example, out of our 396 transcribed sequences, 205 were classified as formulaic, 15 of which were repetitive (most of the time they were a repetition of the teacher's previous utterance), which amounts to $55,6 \%$ of the corpus being classified as non-creative. However, these statistics, like any statistics, are relative since they might depend on the way the sequences are selected and delimited. Nevertheless, it is true that non-creative speech seems to make up a big part of the children's speech in this particular situation.

\begin{tabular}{|c|c|c|}
\hline & Number of sequences & Percentage of total sequences \\
\hline \hline Formulaic utterance & 161 & $40.7 \%$ \\
\hline $\begin{array}{c}\text { Repetition of formulaic } \\
\text { utterance }\end{array}$ & 44 & $11.1 \%$ \\
\hline $\begin{array}{c}\text { Repetition of previous non-FS } \\
\text { TOTAL “NON-CREATIVE" }\end{array}$ & 15 & $3.8 \%$ \\
\hline \hline TOTAL “CREATIVE" & 220 & $\mathbf{5 5 . 6 \%}$ \\
\hline
\end{tabular}

Table 2: Assessment of the respective amounts of non-creative and creative speech 
Corpus linguistics has also estimated the amount of formulaic sequences in native speakers' speech to exceed $80 \%^{2}$ (Altenberg, 1998, in Wray, 1999). Either non-native speakers use more than $80 \%$ of formulaic sequences in their early interlanguage speech and progressively replace them by more creative structures, and finally reach this amount of $80 \%$, or they actually use it less than that and gradually develop a formulaic speech system. Baigent's (1996) findings tally with the second theory. After observing two native speakers and four non-native advanced speakers of English, she found that:

There were many similarities between the native speakers and the non-native speakers' use of chunks of language: the range of types used, task-specific tendencies, individual tendencies and preferences for particular expressions. (...)

However, some differences also emerged: The native speakers used proportionally more chunks than the non-native speakers. Native speaker chunks tended to be more topicspecific and included idiomatic expressions with precise discoursal functions in a way not seen in the non-native speaker output. Non-native speaker errors suggest some interesting shortcomings in the perception and use of chunks.

\begin{tabular}{|c|c|c|c|c|c|c|}
\hline & NS1 & NS2 & NNS1 & NNS2 & NNS3 & NNS4 \\
\hline $\begin{array}{c}\text { AVERAGE } \\
\text { NUMBER OF } \\
\text { MUNKS PER } \\
\text { MINUTE }\end{array}$ & 9.08 & 7.92 & 6.38 & 4.14 & 4.61 & 8.32 \\
\hline $\begin{array}{c}\text { RANK IN } \\
\text { FLUENCY* }\end{array}$ & - & - & $2^{\text {nd }}$ & 4th & $3^{\text {rd }}$ & $1^{\text {st }}$ \\
\hline
\end{tabular}

*The rank in fluency was estimated by several groups of teachers.

Table 3: Compared use of FS between native and non-native speakers. (Baigent, 1996)

Ellis (1994: 88) suggests that "the task facing the learner is not just that of acquiring a rule-system but also of mastering a set of lexicalised sentence stems that will enable him or her to process language efficiently". Another possibility would be that, like morphological developmental stages, the formulaic stage might be followed by an analytical stage to finally give way to a freer use of formulaic sequences according to different processing options.

For Skehan (1998: 53), there are two systems of learning which vary from learner to learner:

[The rule based-system] regards development in terms of the growth and complexity of the underlying system involved, while exemplar-system is more concerned with the accumulation of

${ }^{2}$ These figures might depend on what exactly is being counted and the nature of the texts examined. 
exemplars, and their utility in performance; there is evidence for both structural learning and exemplar-based learning.

So maybe FS belongs to a larger exemplar-based learning strategy parallel to structural learning, in which the learning process would consist in accumulating formulaic sequences.

Second language acquisition phenomena are often described in terms of developmental stages. For example, much work has been done on the acquisition of negation patterns and on morphological development (Cook 1993). As we observed in another study (Girard \& Sionis 2003), Nattinger and De Carrico (1992: 19) suggest that formulas are form/function composites. A formulaic form is learned in terms of its functions. In FS, function has precedence over form; therefore it is more relevant to consider formulas from a pragmatic rather than a syntactic point of view. The notion of pragmatic developmental patterns should also be considered, and FS seems to be a good example to illustrate that type of evolution.

Thus, it is clear that FS is not only an interlanguage short-term production strategy used as a response to a lack of structural knowledge (since it is also found in the speech of native speakers who presumably have full structural knowledge), but also a learning strategy which corresponds to choices in processing made by the learner. Analysis of our corpus shows that formulaic language plays a part in a psycholinguistic production strategy particularly useful for second language learners.

\section{Psycholinguistic function}

There is an aspect of FS in language use which is related to the fields of psycholinguistics and pragmatics. In this perspective, FS can be seen as a production strategy. What we mean is that the use of FS increases fluency and also allows the pre-planning of more creative constructions, which relates the use of FS to the concept of economy in language use. Therefore it is necessary to insist on the role of economy and memory: Formulaic sequences are used as "islands of reliability"(Dechert 1984) by learners. It allows them to economize effort bearing on the structural frame and concentrate on the message they want to convey. Since learners spend less time thinking, they talk more fluently. Baigent's (1996) findings illustrate that fact, by revealing a correlation between fluency and the amount of formulaic sequences used (Table 2). Fluency however is difficult to define, and even harder to measure, and it was not possible for us to draw any conclusions on fluency from our own data.

\subsection{Pre-planning strategy}

Raupach (1984: 123) and Nattinger and De Carrico (1992) classify formulaic utterances according to their function in discourse planning and organization. According to Raupach (1984: 123), "not only do these items contribute to the argumentative or narrative structure of parts of the performance, their respective use reflects the relatively small repertoire of cognitive structures the learners are able to verbalize". In the case of the speech used by the 
children in the partial immersion classroom, no such thing was observed since they were not given the opportunity to tell stories or to produce argumentative discourse.

However, on a smaller scale, the children used formulaic sequences as props to contribute new information. All the observed productions concerned "likes" and positive notions like being given sweets, fruit, etc. Eventually, the same set of exchanges moved towards "dislikes", and the correct inclusion of the abbreviated form "don't" had then been prepared by the affirmative forms.

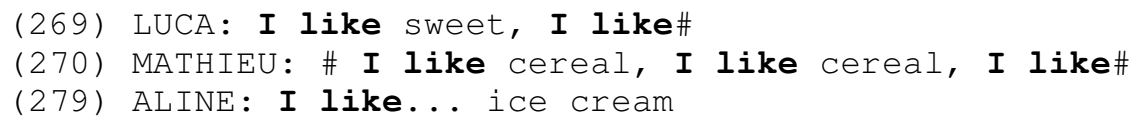

Most of all, the phenomenon occurred when asking for permission, with the prompt "Can I __", sometimes followed by a hesitation pause which indicated that the child was planning the next speech production:

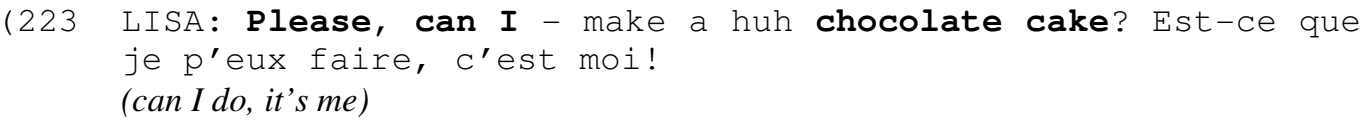

However, it seems that in the following sequences

(328) ALINE: Can I - read?

(333) ALINE: Sit huh. Comment on dit can I emm

this was the very exercise that the children were asked to perform, since they were given a test in which they had to ask the questions corresponding to a mime done by the teacher.

Wray (2000) analyses the various functions of FS in the reduction of the learner's processing load. Examples from our data are in bold. Otherwise, the rest of the table is taken from Wray (2000).

FS therefore benefits the learner's production because it helps him or her structure his or her discourse and economize effort on processing. But resorting to FS is also an effort-saving way to acquisition since it reduces the learner's processing load and thus helps him or her to concentrate on acquisitional problems. 


\begin{tabular}{|c|c|c|c|}
\hline Function & Effects & Types & Examples \\
\hline \multirow[t]{2}{*}{$\begin{array}{l}\text { Processing } \\
\text { short-cuts }\end{array}$} & \multirow[t]{2}{*}{$\begin{array}{l}\text { Increased production, } \\
\text { speed and fluency }\end{array}$} & $\begin{array}{c}\text { Standard phrases (with or } \\
\text { without gaps) }\end{array}$ & $\begin{array}{l}\text { Can I have __? } \\
\text { What time is it? }\end{array}$ \\
\hline & & $\begin{array}{l}\text { Standard referential } \\
\text { labels with agreed } \\
\text { meanings }\end{array}$ & Chocolate cake \\
\hline \multirow[t]{5}{*}{ Time-buyers } & \multirow{5}{*}{$\begin{array}{l}\text { a)Vehicles for fluency, } \\
\text { rhythm and emphasis } \\
\text { b)Planning time } \\
\text { without losing the turn }\end{array}$} & $\begin{array}{l}\text { Standard phrases with } \\
\text { simple meanings }\end{array}$ & Have a party \\
\hline & & Fillers & $\begin{array}{l}\text { If the truth be told, if you want } \\
\text { my opinion, if you like }\end{array}$ \\
\hline & & Turn-holders & $\begin{array}{c}\text { And another thing, and let me } \\
\text { just say }\end{array}$ \\
\hline & & $\begin{array}{l}\text { Discourse shape } \\
\text { markers }\end{array}$ & $\begin{array}{c}\text { There are three points I want to } \\
\text { make. } \\
\text { Firstly...Secondly...Lastly }\end{array}$ \\
\hline & & $\begin{array}{l}\text { Repetitions of } \\
\text { preceding input }\end{array}$ & $\begin{array}{c}\text {-Mathieu, What time is it? } \\
\text {-What time is it! It's six } \\
\text { o'clock }\end{array}$ \\
\hline \multirow[t]{3}{*}{$\begin{array}{l}\text { Manipulation } \\
\text { of information }\end{array}$} & \multirow{3}{*}{$\begin{array}{l}\text { Gaining and retaining } \\
\text { access to information } \\
\text { otherwise unlikely to be } \\
\text { remembered }\end{array}$} & Mnemonics & $\begin{array}{c}\text { Thirty days hath September... } \\
\text { Richard of York gave battle in } \\
\text { vain }\end{array}$ \\
\hline & & $\begin{array}{l}\text { Lengthy texts one is } \\
\text { required to learn }\end{array}$ & Jingle Bells \\
\hline & & Rehearsal & $\begin{array}{l}\text { Rehearsing a phone number } \\
\text { while looking for a pen }\end{array}$ \\
\hline
\end{tabular}

Table 4: The functions of FS in reducing processing effort

\subsection{An effort-saving way to acquisition}

Not only do formulaic sequences have a function in pre-planning and organizing discourse, but they also provide time for other types of processing, and help the learner to concentrate on other aspects of his or her second language use, and thereby facilitate acquisition.

In what follows, Mathieu's rephrasing seems to indicate that he is actually able to parse a formulaic sequence "I'm not __".

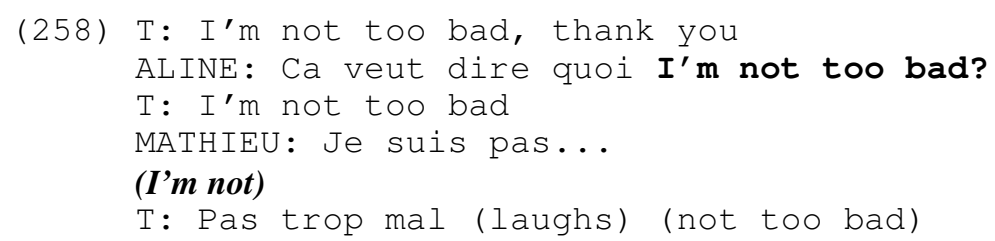


MATHIEU: Pas trop mal, pas trop mal, pas\#

Lehtonen (1985: 38) gives a psycholinguistic account for this fact by distinguishing two ways of processing language: Automatic and controlled processing:

Controlled processing requires attention and decreases the system capacity which is available for other processing. Automatic processing does not necessarily demand processing resources, which means that there is capacity in the system for higher-level processing. The distinction between controlled and automatic processing is related to the degree to which the skills in question have been routinized and established in long-term memory

The use of FS requires less effort than creative speech, because "the process of modifying a practised sequence internally is psychologically more complex than the process of collocating linguistic units" (Clark 1974: 7).

FS can then be seen as a network of semantic, lexical, grammatical, textual and pragmatic associations which facilitate processing (Lehtonen, 1985, 38). Indeed, it seems to be an efficient effort-saving device which gives time for other types of processing, and consequently is a good route towards acquisition, because, as Porto (1999) suggests,

learners do not need to pay attention to grammar if they use [formulaic sequences]. By shifting their attention from grammar to features such as relevance, coherence and appropriateness, learners are able to organize their speech at discourse level and maintain the flow of conversation

Even when FS is a mere repetition, it may play a role in the acquisition process. Indeed, for Skehan (1998: 32) "repetition in conversation can serve to consolidate what is being learned, since the conversation may act as an obtrusive but effective scaffold for what is causing learning difficulty".

The psycholinguistic function of FS to spare effort in interlanguage use has two advantages for the learner: It leads to greater fluency and gives time for pre-planning activities or other types of processing therefore providing a prop for acquisition processes.

\section{Communicative function}

\section{Formulaic Speech as a social integration device}

FS may be produced as a response to communicative pressure. This notion of communicative pressure is twofold: FS helps the learner to adapt an utterance to the context, but also on a larger scale helps the child to integrate a given community, because it is bound to the rules of that community.

FS is strongly linked to the communicative needs of the classroom situation, and it is more likely to appear in very socially and culturally defined situations. Therefore, learners have to be able to comprehend the communicative situation to adapt to the native speaker community. Formulaic sequences are efficient tools that allow learners to make themselves understood quickly and easily by native hearers.

Rescorla and Okuda (1987) suggest that FS in naturalistic L2 acquisition is a way of integrating the community. Wray (2000) also points to the fact that 
A number of taxonomies of formulaic sequences (or subsets of them), most notably those of Nattinger and De Carrico (1992) (...) are based on the socio-interactional function that some of them have, for greeting, thanking, apologizing, and so on. Many of such functions seem to rely on the use of agreed forms to a greater or lesser extent. (Also) the selection of a formulaic sequence in the socio-interactional context aims to achieve the maximum chance of efficient comprehension

In fact, Wray (2000) hypothesizes that, while the psycholinguistic role of FS is to ease processing for the speaker, its socio-linguistic role is to ease processing for the hearer. According to her:

(...) the success of the utterance [is measured] by whether the hearer reacts appropriately, be that in providing a requested item, backing down in the face of a threat, or registering the speaker as an in(or out-) group member. (...) the most important observation is that all formulaic sequences can be characterized in terms of their function in bypassing processing, whether it be the speaker's or the hearer's, or both. (Wray 1999)

In anticipated support of Wray's theory, Skehan (1991: 82) suggests that "much communication relies upon lexicalised chunks of language which are necessary for the speaker to keep up with real time, and for the listener to avoid having to deal with consistently new and difficult-to-process language"

Wray (2000) synthesizes speaker-hearer interaction with FS in table 5.

FS is more likely to be used in very routine social interaction situations. For example, according to Hatch (1983: 172-173), there is a relationship between FS and children's games:

The language of games is predictable and repetitive (e.g. my turn, my side, give it to me, throw it here, I win, get out of here, etc.). Such chunks are quickly learned and their use gives the learner easy access to social interaction on the playground. More formal indoor games also have many high frequency formulas that the child can use to perform a part in these mini speech events. Lily Wong-Fillmore's data (1976) showed a very large number of "formulaic utterances" (not all of them are from language during play, but certainly a high percentage appear to be).

For Krashen and Scarcella (1978), Fillmore's analysis (1976) clearly shows that under certain conditions the "gestalt" mode may be encouraged to a remarkable degree, but it does not demonstrate that the whole of language is acquired this way by all learners. So it seems that in very routinized social interaction, FS is largely preferred, which correlates with its socio-linguistic role. Therefore, this very socio-linguistic role might determine what learning mode the learner is going to resort to, and therefore play a part in the acquisition process.

For Klein (1986), FS contributes to the communicative success and social integration of the learner. However, in the classroom role-playing sessions we observed, social interaction seemed artificial because it was only reached through role-playing, which is one of the drawbacks of this partial immersion program. Indeed, one of the key processes at work in acquisition is the desire to identify with the native speaker and to integrate the native speaker community, a phenomenon referred to as integrative motivation, which can be reached by genuine contact with native speakers. Apart from their teacher, the children are not confronted with real social interaction with native speakers. It might be deduced that the socio-linguistic role of FS in learner language is more likely to appear in naturalistic acquisition, and that it is not quite as developed in classroom situations. 


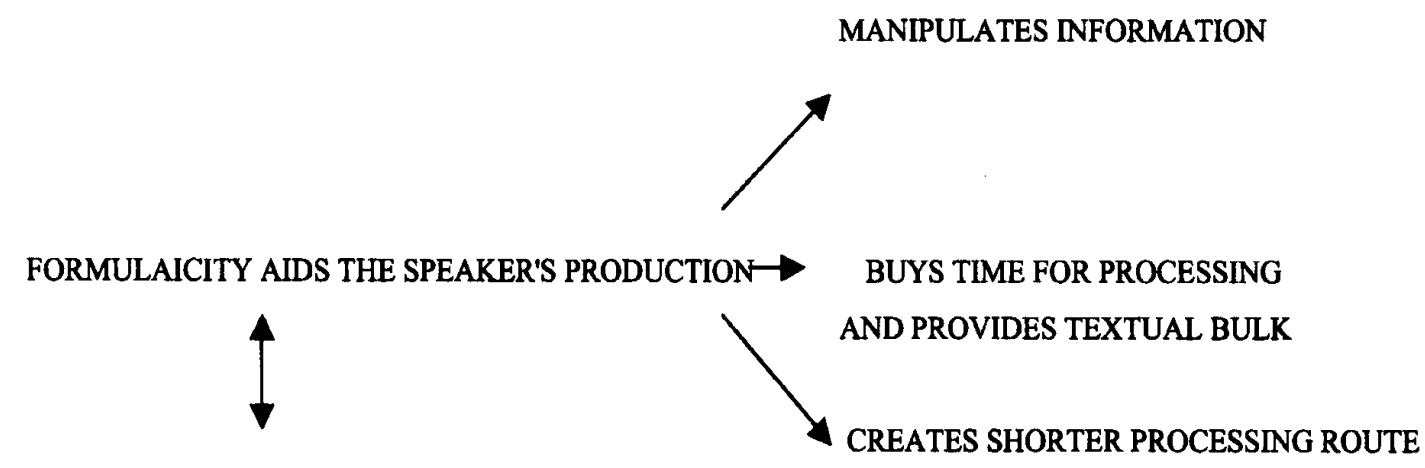

FORMULAICITY BENEFITS THE SPEAKER

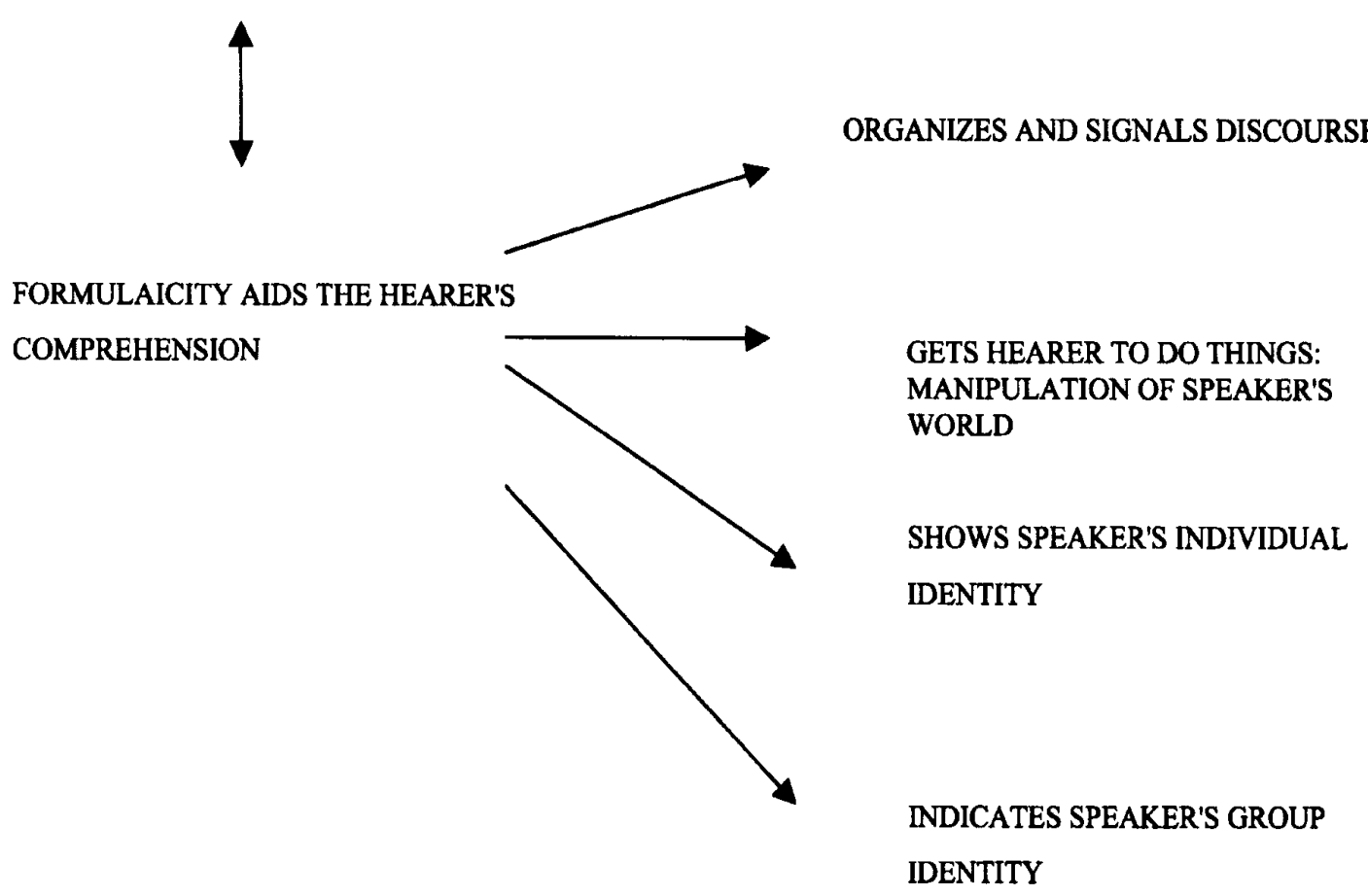

Table 5: Benefits of formulaicity for the hearer

According to Wray (2000), "Gaining full command of a new language requires the learner to become sensitive to the native speakers' preferences for certain sequences of words over others that might appear just as possible". FS is a way for the learner to reach idiomaticity.

Although the socio-linguistic function of FS was not clearly at work in our observation, it seems that it might play a role in helping the learner reach idiomaticity in more or less routine situations (which determine the learning mode the learner is going to choose). FS facilitates processing not only for the speaker but also for the hearer.

So, more than a learning and production strategy, FS appears to be an efficient communication strategy, benefiting both the speaker and the hearer by easing processing and facilitating adaptation to the context. FS plays a part at all levels of the acquisition process, thereby acting as both a language-learning strategy and a skill-learning strategy. 


\section{Conclusion}

FS is situated on a continuum from a mostly flexible to a mostly fixed type of language, the "fixedness" of which can be found at linguistic, communicative and socio-cultural levels. This continuum corresponds to two poles of language development, one being analytic and the other "gestalt". So, as a real component of language use, FS is not only a temporary stage of acquisition, but also a processing strategy that benefits both the speaker and the hearer. It benefits the speaker's production by giving him or her time for discourse planning or other types of processing effort, and it also economizes processing to the hearer, who processes a sequence more easily if it is formulaic than if it is more creative. Thus, FS helps the learner reach idiomaticity and thereby efficient communication in his or her second language with native speakers.

All the functions of FS in learner production seem to lead to acquisition, by helping the development of both linguistic and pragmatic competence. In more precise terms, FS might be an important factor in the development of the learner's communicative competence. Moreover, since FS is at the interface between linguistics and pragmatics, it is an interesting subject to investigate in psycholinguistics and neurolinguistics too, to determine the processes at work behind the development of communicative competence. The study we carried out is based on short-term observation, and we could not investigate these fields in depth because they require long-term data.

Not only has the partial immersion program observed given us insights into the nature and functions of FS, but it has also reflected a teaching tradition that does not correspond to the concept of immersion. In fact, parents and authorities fear that children might start mixing up languages if their education is given in another language. Yet, early language education is popular and so this program seems to find a compromise between these two paradoxical facts. We focused this study on the learner and did not intend to bring about language teaching issues. However, research on FS in interlanguage use is a wide field of study which could lead to interesting new classroom techniques.

\section{References}

Aijmer, K. (1998) Conversational Routines in English. London: Longman.

Altenberg, B. (1994) On the phraseology of spoken English: The evidence of recurrent word combinations. In Cowie (ed.), 1994.

Arends, J., P. Muysken, \&. N. Smith (eds.) Pidgins and Creoles: An Introduction. Amsterdam: John Benjamins.

Baigent, M. (1996) Speaking in Chunks: An investigation into the use of multi-word phrases in spoken language by advanced learners of English. MSc Thesis in Teaching English, Aston University.

http://www.les.aston.ac.uk/lsu/diss/m.baigent.html

Bohn, O. (1986) Formulas, frame structures, and stereotypes in early syntactic development: Some new evidence from L2 acquisition. Linguistics 24: 185-202.

Brown, R. (1973) A First Language. Cambridge: Harvard Press 
Clark, R. (1974) Performing without competence. Journal of Child Language 1: 1-10.

Cook, V. et al (1993) Linguistics and Second Language acquisition. London: Macmillan.

Cowie, A. (ed.) (1994) Phraseology: Theory, Analysis and Applications. Oxford: Oxford University Press.

Dechert, H., D. Möhle, and M. Raupach (eds.) (1984) Second Language Productions. Tübingen: Narr.

Ellis, R. (1994) The Study of Second Language Acquisition. Oxford: Oxford University Press.

Girard, M., \& C. Sionis (2003) Formulaic Speech in the L2 Class: An Attempt at identification and Classification. Pragmatics 13.2: 231-251.

Givón, T. (1979) From Discourse to Syntax. Grammar as a processing strategy. In T. Givón (ed.), Discourse and syntax (Syntax and Semantics 12) New York: Academic Press, pp. 81-111.

Hakuta, K. (1974) Prefabricated patterns and the emergence of structure in second language acquisition. Language Learning 24: 287-97.

Hamers, J.F., and M. Blanc (1989) Bilinguality and Bilingualism. Cambridge: Cambridge University Press.

Hatch, E.M. (1972) Some Studies In Language Learning. UCLA Workpapers on Teaching English as a Second Language 6: 29-36.

Hatch, E.M. (1983) Psycholinguistics. A second language perspective. Rowley, Mass.: Newbury House.

Kecskes, I. (2000) A cognitive-pragmatic approach to situation-bound utterances. Journal of Pragmatics. 32.6: 605-625.

Klein, W. (1986) Second Language Acquisition. Cambridge Cambrige University Press.

Krashen, S , and R. Scarcella (1978) On routines and patterns in second language acquisition and performance. Language Learning 28: 283-300.

Krashen, S., M. Long, and R. Scarcella. (1979) Age, rate and eventual attainment in second language acquisition. TESOL Quarterly 13: 573-82.

Larsen-Freeman, D., and M.H. Long (1991) An introduction to second language acquisition research. London: Longman.

Lehtonen, J.( 1985) Foreign Language Acquisition and the Development of Automaticity. In H. Dechert (ed.), 1990. Current Trends in European Second Language Acquisition Research. Clevendon, Avon: Multilingual Matters.

Manuel, J. (1990) Ecole Active Bilingue: Teacher's guide. Paris R.E.M.I. Nathan.

Nattinger, J., and J. De Carrico (1992) Lexical Phrases and Language Teaching. Oxford: Oxford University Press.

Peters, A.M. (1976) Language learning strategies: Does the whole equal the sum of the parts? Language 53: 560-73. 
Peters, A.M. (1983) The units of Language Acquisition. Cambridge: Cambridge University Press.

Pierce, A. (1992) A comparative analysis of French and English Child Grammar. Dordrecht: Kluwer.

Porto, M. (1998) Lexical phrases and language teaching. Forum 36.3: 22.

http://exchanges.state.gov/forum/vols/vol36/no3/p22.htm

Radford, A. (1997) Syntactic theory \& the structure of English. Cambridge: Cambridge University Press.

Radford, A.(1998) Syntactic Theory and the Acquisition of English Syntax. Cambridge: Cambridge University Press.

Raupach, M. (1984) Formulae in second language production. In H. Dechert et al. (eds.), Second Language Productions. Tübingen: Narr.

Rescorla, L., and S. Okuda (1987) Modular patterns in second language acquisition. Applied Psycholinguistics 8: 281-308.

Schmidt, R.W. (1983) Interaction, acculturation, and the acquisition of communicative competence: A case study of an adult. In N. Wolfson and E. Judd (eds.), Sociolinguistics and Language Acquisition. Rowley, MA.: Newbury House, pp. 137-74.

Singh, I. (2000) Pidgins and Creoles, an Introduction. London: Arnold.

Skehan, P. (1998) A Cognitive Approach to Language Learning. Oxford: Oxford University Press.

Taylor, J.R. (1989) Lexical Categorization. Oxford: Oxford University Press.

Wagner-Gough, J. (1975) Comparative Studies in second language learning. CAL ERIC/CLL Series on Languages and Linguistics 26.

Wong-Fillmore, L. (1976) The second time around: Cognitive and social strategies in SLA. Language Learning 32: 53-68.

Wray, A. (2000) Formulaic sequences in second language teaching: Principle and practice. Applied Linguistics 21.4: 463-489.

Wray, A. (2002) Formulaic Language and the Lexicon. Cambridge: Cambridge University Press. 